\title{
SIGNIFICAÇÕES DA DOCÊNCIA EM ARTE NA EDUCAÇÃO PROFISSIONAL E TECNOLÓGICA
}

\author{
Luana Cassol Bortolin*; Vantoir Roberto Brancher \\ *E-mail: luana.cassol@hotmail.com \\ Instituto Federal de Educação, Ciência e Tecnologia Farroupilha; Instituto Federal de \\ Educação, Ciência e Tecnologia Farroupilha \\ DOI: 10.15628/rbept.2020.9375
}

Artigo submetido em jan/2020 e aceito em abr/2020

\begin{abstract}
RESUMO
Este artigo tem como objetivo discutir as significações da docência em arte na educação profissional e tecnológica. Partiu-se da necessidade em saber como o professor de arte se vê e se percebe neste contexto. Logo, foi conduzida uma entrevista semiestruturada com um docente de arte atuante desta circunstância. Conforme a metodologia qualitativa de pesquisa contou-se com análise de conteúdo para a categorização das narrativas (BARDIN, 2016) e autores como Castoriadis (1982), Ferreira (2006), Brancher e Oliveira (2007) referenciaram teoricamente as interpretações e discussões dos dados. A partir das narrativas coletadas na entrevista foi possível aproximar-se das representações da docência em arte. Observaramse, assim, os desafios enfrentados em relação ao ensino de arte na educação profissional e como a formação permanente dos docentes é necessária para a melhoria desta condição.
\end{abstract}

Palavras-Chave: representações de docência. ensino de arte. educação profissional e tecnológica

\section{MEANINGS OF ART TEACHING IN VOCATIONAL AND TECHNOLOGICAL EDUCATION}

\begin{abstract}
This article aims to discuss the meanings of teaching in art in professional and technological education. Participate in the need to know how the art teacher sees and perceives in this context. Then, a semi-structured interview was conducted with an art document active in this circumstance. According to a qualitative research methodology reported with content analysis for the categorization of narratives (BARDIN, 2016) and authors such as Castoriadis (1982), Ferreira (2006), Brancher and Oliveira (2007) refer theoretically as interpretations and discussions of the data. From the narratives collected in the interview, it was possible to approach the representations of teaching in art. It was observed, therefore, the challenges faced in relation to art teaching in the integrated curriculum and how the permanent formation of documents is necessary to improve this condition.
\end{abstract}

Keywords: teaching representations. art teaching. professional and technological education 


\section{INTRODUÇÃO}

Este artigo tem como objetivo discutir as significações da docência em arte no contexto da educação profissional e tecnológica. Como analisamos as representações de docência, foi possível pensar com mais afinco sobre a formação de professores.

Num breve rememorar histórico sobre o ensino de arte no país, Barbosa (2007) demonstra que várias influências teóricas construíram o campo da educação e a arte passou por diferentes visões/representações que reverberam até hoje.

O ensino de arte no Brasil foi trabalhado de maneira elitista quando datado no período acadêmico da época Imperial. Na Academia Imperial de Belas Artes, criada em 1816, artistas estrangeiros ensinavam o desenho e a pintura de maneira realista e acadêmica para uma pequena elite local.

No período Republicano, abarcou as influências da Escola Nova, onde os estudos de John Dewey e da psicologia tomaram conta do ensino e a expressividade foi de ampla importância na arte. Mas, na escola, a arte ganhou mais visibilidade e interação com o público do que na época imperial.

Em outro momento, o tecnicismo também embasou as concepções de ensino no país. Esse fato tornou por algum tempo a educação brasileira pragmática e dedicada exclusivamente a resultados. Consequentemente, o ensino da arte também sofreu estas interferências. Inclusive, neste período, a Lei n. 5.692/71 trouxe a obrigatoriedade da arte nos currículos escolares, mas com características tecnicistas. (FERRAZ; FUSARI, 1992).

$\mathrm{Na}$ educação profissional, o ensino de arte, anteriormente, era voltado ao desenho, principalmente o geométrico que fosse aplicável para o desenvolvimento do trabalhador nos setores industriais posteriormente. Porém, hoje o cenário da educação profissional é outro. Com a expansão da Rede Federal de ensino, tem-se como objetivo principal a formação humana plena, a formação para o mundo do trabalho. $O$ ensino de arte, neste contexto, pede pelo desenvolvimento da sensibilidade, da estética, da percepção, da compreensão crítica da sociedade e da cultura.

Logo, após traçarmos este panorama sobre o ensino de arte é preciso este olhar para o novo contexto da educação profissional. Como hoje este professor de arte se vê? $O$ objetivo desta pesquisa é compreender as representações de docência e como estes dados podem contribuir de algum modo para pensar sobre a formação de professores na educação profissional e tecnológica. 


\section{FORMAÇÃO DE PROFESSORES E EDUCAÇÃO PROFISSIONAL E TECNOLÓGICA}

A expansão da Rede Federal Tecnológica de ensino com a criação dos Institutos Federais pela lei 11.892/2008 trouxe demandas imediatas de professores para atuar no ensino tecnológico. Segundo Maldamer (2007), é perceptível os desafios impostos aos professores neste contexto tanto pelas mudanças ocorridas nas estruturas do mundo do trabalho como pelas políticas públicas da educação profissional e tecnológica. Este mesmo autor ainda acrescenta que:

\footnotetext{
Desafios que requerem do professor da EPT uma formação consistente, pois no seu fazer cotidiano lida com as técnicas, as tecnologias, a ciência e precisa transpor isso didaticamente para seus alunos. Precisa ensinar sem que, na maioria dos casos, tenha tido formação pedagógica para tal. (MALDAMER, 2007, p. 183)
}

Deste modo, Moura (2008) também questiona estas circunstâncias da formação de professores na educação profissional, como algo que exige algumas concepções diferenciadas. Esse autor indaga: "Formação de Professores para que Educação Profissional e Tecnológica?" (MOURA, 2008, p.25). Assim traz a necessidade de formação permanente para os profissionais coerentes com as reais necessidades educacionais, como exemplo, a própria formação didática-político-pedagógica.

Essa discussão refere-se a que não basta um profissional possuir técnicas para o ensino, mas que esteja consciente de seu papel como docente para além da explanação de conteúdo. Como exemplo, a educação bancária que Freire (1970) aborda, onde o aluno é um receptor passivo do conhecimento e o professor um narrador que deposita e transmite saberes aos estudantes.

Os conteúdos na educação bancária são retalhos da realidade e não tecem relações com a totalidade, com a complexidade e nem com a vivência do estudante. Este modelo de ensino hoje não serve mais, principalmente no contexto dos Institutos Federais que preconizam a formação humana integral.

Do mesmo modo, Candau (2012) trata a didática como multidimensionalidade no processo de ensino em que o técnico, o humano e o sócio-político estejam sempre articulados. Por isso, a educação profissional e tecnológica, hoje, requer um professor crítico, reflexivo que saiba despertar nos alunos a consciência sobre a ciência, cultura, tecnologia e o mundo do trabalho estando assim trabalhando com a práxis educativa.

O conhecimento das questões políticas e pedagógicas dos Institutos Federais tem como filosofia a integração dos conhecimentos para a formação plena dos estudantes e a não separação do trabalho manual e intelectual. Isso traz desafios inerentes à instituição. Neste sentido, Moura (2008) cita os 
professores como os principais sujeitos envolvidos no processo de formação dos alunos e precisam estar atentos com o objetivo da educação profissional e tecnológica.

Indagarmos sobre a formação de professores para qual educação profissional significa a preocupação com o objetivo de que sociedade se visa construir. Apesar do neoliberalismo, é possível pensar numa sociedade "na qual a ciência e a tecnologia estejam submetidas a uma racionalidade ética ao invés de estarem, quase exclusivamente, a serviço do mercado e do fortalecimento dos indicadores econômicos." (MOURA, 2008, p.25)

Logo, é preciso que ultrapassem os limiares da educação bancária, pois o objetivo do currículo integrado é superar uma educação profissional que vise à formação de "mão-de-obra" para fortalecer a economia e o mercado. Os professores são principais agentes de formação e precisam assumir uma postura que oriente para a responsabilidade social.

Moura (2008) traz algumas orientações na formação de professores para atuação na educação profissional. Além de terem conhecimentos específicos de sua área de atuação, é necessário que os docentes tenham uma formação didático-político-pedagógica e trabalhem pelo diálogo com a sociedade e o mundo do trabalho.

Por isso, faz-se necessária também uma reflexão sobre aqueles professores que já atuam na educação profissional e a necessidade de formação permanente. Imbernóm (2010) traz o conceito de formação permanente para o professorado, em que na docência é preciso reflexão contínua, colaboração entre colegas e atividade de pesquisa sobre suas práticas.

Faz-se necessária a formação permanente na educação profissional a fim de um clima de colaboração institucional em que se reflita conjuntamente a problemática sobre trabalho e educação. Deste modo, permita também a conversação para a diminuição da fragmentação curricular. Neste caso, o currículo integrado não é instantâneo, exige colaboração coletiva de todos os profissionais da instituição, logo temos aqui um grande objetivo de pensarmos sobre a formação de professores dentro dos Institutos Federais.

\section{METODOLOGIA}

Este estudo caracteriza-se por investigar sobre a formação de professores na área da educação básica profissional e tecnológica. Dessa forma, esta investigação organizar-se-á a partir dos pressupostos da pesquisa qualitativa, que segundo Triviñus (1987) significa:

[...] por um lado, que ela compreende atividades de investigação que podem ser denominadas específicas. E, por outro, que todas elas podem ser caracterizadas por traços comuns. Esta é uma ideia fundamental que pode ajudar a ter uma visão mais clara do que 
pode chegar a realizar um pesquisador que tem por objetivo atingir uma interpretação da realidade do ângulo qualitativo. (p.121)

A entrevista semiestruturada foi realizada com uma colaboradora docente de arte de um Instituto Federal afim de termos uma melhor aproximação sobre as representações de docência e discutirmos sobre a formação de professores. Segundo Triviñus (1987, p.146) a entrevista semiestruturada é aquela que:

[...] parte de certos questionamentos básicos, apoiados em teorias e hipóteses, que interessam à pesquisa, e que, em seguida, oferecem amplo campo de interrogativas, fruto de novas hipóteses que vão surgindo à medida que se recebem as respostas do informante. Desta maneira, o informante, seguindo espontaneamente a linha de seu pensamento e de suas experiências dentro do foco principal colocado pelo investigador, começa a participar na elaboração do conteúdo da pesquisa.

$\mathrm{Na}$ pesquisa qualitativa as entrevistas semiestruturadas auxiliam na aproximação com o colaborador por ser um instrumento onde as falas, os gestos, a expressão do sujeito também são importantes para a compreensão da realidade. A realização da entrevista foi previamente anunciada para a colaboradora, com hora e data marcada, com gravador de voz e roteiro de perguntas estabelecidas. Teve duração de duas horas num espaço sem interferências e privado.

Por ordens éticas de pesquisa tivemos a Carta de Apresentação, a assinatura do Termo de Consentimento Livre e Esclarecido e o Termo de Confidencialidade. Caso não ocorresse a leitura e a assinatura de tais termos seria um critério de exclusão para que o andamento da entrevista não acontecesse.

Através das narrativas da entrevistada se fez a categorização com a análise de conteúdo de Bardin (2016) que consiste em: a pré-análise, a exploração do material, o tratamento dos dados e a interpretação. A primeira fase com a pré-análise é o período de sistematizar as ideias iniciais de acordo com os objetivos da pesquisa. Na segunda etapa com a exploração do material deve-se fazer recortes e categorizações conceituais das sucessivas repetições de palavras e enunciações para depois a interpretação dos dados.

A análise e interpretação terá em vista a compreensão das representações de docência do professor entrevistado. Esta compreensão trará uma repercussão para discutir a docência em arte no âmbito da educação profissional e de que modo pode ser complementada a percepção sobre a mesma. 


\section{ANÁLISE E DISCUSSÃO DOS DADOS}

Para a realização da amostra foi realizada a entrevista com uma colaboradora professora de arte em um Instituto Federal. Antes do roteiro de entrevista foi elaborado um perfil para a docente. A fim de manter sigilo de sua identidade, foi utilizado um nome fictício "Professora Frida".

Quadro 1 - Perfil do Participante da Pesquisa

\begin{tabular}{|l|c|c|c|}
\hline \multicolumn{1}{|c|}{$\begin{array}{c}\text { Identificação } \\
\text { (Nome Fictício) }\end{array}$} & $\begin{array}{c}\text { Tempo } \\
\text { de Docência } \\
\text { Ensino Superior e } \\
\text { Educação Básica }\end{array}$ & $\begin{array}{c}\text { Tempo de } \\
\text { Docência na } \\
\text { Instituição/EBPT }\end{array}$ & $\begin{array}{c}\text { Titulação/ } \\
\text { Formação }\end{array}$ \\
\hline $\begin{array}{l}\text { Professora } \\
\text { Frida }\end{array}$ & 25 anos & 2 anos & $\begin{array}{c}\text { Mestre em } \\
\text { Educação } \\
\text { Especialista } \\
\end{array}$ \\
& & & $\begin{array}{c}\text { Educhação } \\
\text { Eartes Visuais }\end{array}$ \\
\hline
\end{tabular}

Fonte: Elaboração própria, 2019.

Como visível no quadro acima, a amostra contou com uma professora com tempo de carreira docente tanto no ensino superior como na educação básica antes de ingressar na educação profissional e tecnológica. Também é visível que a participante possui titulação de Mestre em Educação, Especialista em Informática na Educação e formação de graduação Bacharel em Artes Visuais.

O fato desta docente não ter a formação de Licenciatura ou formação pedagógica influencia consideravelmente em seu trajeto de formação e sua descoberta enquanto professora. Este dado auxilia também para compreender e ver como as representações de docência se consolidam.

\section{REPRESENTAÇÕES DE DOCÊNCIA: DESAFIOS PARA FORMAÇÃO DE PROFESSORES}

A formação de professores é importante de ser pesquisada na EBPT em função do perfil, identidade política e pedagógica da instituição a favor da transformação social, além de possuir um currículo voltado à integração. (MOURA, 2008). 
Neste contexto, há necessidade de discutirmos sobre as representações de docência, pois André (2010), a partir do pensamento de Garcia (2009), lembra que pensar a identidade docente "o que é ser professor?" é imprescindível para se questionar crenças e imagens que afetam seu processo de formação:

[...] nesses processos de desenvolvimento profissional, deve-se dar grande importância às representações, crenças, preconceitos dos docentes porque vão afetar sua aprendizagem da docência possibilitar ou dificultar mudanças. Torna-se, pois, necessário vir a tona essas representações e analisá-las criticamente junto aos professores para poder encontrar formas de transformá-las na direção desejada. (p.176).

Logo, trabalhar com as representações de docência na formação de professores requer pensar imagens estabelecidas de como o profissional percebe-se e produz certos movimentos às suas práticas de ensino. A identidade profissional está ligada aos compromissos, aos valores e às crenças que atribuem características e significados ao "ser professor".

Segundo Narvaes (2000), as imagens que os professores possuem de sua profissão e quais os sentidos veiculados por elas é um fio condutor de muitas reflexões.

Assim, torna-se favorável discutir no âmbito dos Institutos Federais sobre: "O que é ser professor?", "Como me vejo enquanto professor de um Instituto Federal?", "Quais Implicações essas representações de docência trazem a minha prática?". A partir destas perguntas, delimitou-se a necessidade de se aproximar de uma docente de arte atuante na educação profissional.

No primeiro momento, a necessidade de aproximação com uma docente da área de arte se deu porque, segundo Barbosa (2007), o ensino da arte foi trabalhado por muito tempo como "mero fazer" ou "livre-expressão" pela influência escolanovista. E, por outro lado, o ensino de arte na educação profissional, anteriormente, tinha a característica do estudo do desenho geométrico e a aplicação de suas técnicas para o setor industrial.

Isso nos traz a hipótese cujas visões em relação à arte podem trazer uma imagem errônea e desvalorizada em relação a ela. No âmbito dos Institutos Federais, se preconiza a integração dos componentes curriculares, porém os professores estão inseridos num contexto tecnológico e com alta carga-horária para os componentes específicos dos cursos técnicos. Isso traz uma demanda da reflexão sobre o ensino de arte nesta situação.

Neste contexto de pesquisa, é necessário tecer algumas relações às representações de docência deste professor em constante formação, pois, como remete Garcia (2009), não podemos desvincular a identidade do professor do seu desenvolvimento profissional. No que se pode analisar das falas abaixo a partir da coleta de dados, segue-se a perspectiva de que a 
colaboradora, por não ter a formação pedagógica em licenciatura, construiu um processo inserida na sala de aula. Isso representa que para ser professor é imprescindível o contato com o meio:

Pra mim é gostar de gente, não importa onde você vá, a escola que você atua, tem gente lá é lá que você deve estar. Eu não tive formação, eu nunca tive formação em licenciatura, eu não sou licenciada, sou bacharel. A minha formação foi dentro das escolas, mas tem que gostar. Tem que gostar do que se faz. (Professora Frida)

O contato com os alunos na sala de aula, fez com que a professora refletisse sobre sua prática diariamente. Gauthier (2009) assim como Tardif (2008) trazem o conceito de saber experiencial que é o saber docente que se constrói diariamente na prática diária de ensino. Mesmo que a colaboradora tivesse formação em bacharelado, construiu valores e crenças na sua prática de ensino que a identificam enquanto professora.

Em relação ao processo pedagógico da professora na educação profissional, ela possui percepções diferenciadas a respeito do ensino da arte. Uma visão é correspondente aos alunos da instituição, a outra visão é correspondente aos colegas professores:

No IF os alunos te respeitam, te valorizam, eles querem ter arte, adoram, é o momento que eles extravasam, é o momento necessário para eles, eles estão ali naquelas disciplinas intermináveis, naquelas cobranças intermináveis, então quando chega arte, eles dizem: "Ah, agora eu vou respirar, aula de arte" $\mathrm{E}$ eles precisam disso, eu nunca entendi isso como descaso total, uma coisa assim com descaso, não, como se arte fosse qualquer coisa, nunca. Pra mim, eu tenho certeza que aquele momento é o momento extremamente necessário, um momento que eles conseguem se ver como pessoa, conseguem extravasar mais. (Professora Frida)

Mas eu vivenciei no IF, um grupo de professores que eu acho que eles não tinham contato com arte. Então para eles tanto faz se eu me atrasar, tanto faz se um professor colocasse outra aula no meu único período de arte, porque supostamente aquela aula de arte não era importante e a disciplina do outro colega era. (Professora Frida)

Esta mesma dualidade na percepção dos alunos e dos colegas professores persiste em relação ao modo como a professora se sente em meio ao ensino profissional. Isso aparece na seguinte fala de que é considerado a arte uma aula de "extravasar":

Porque é um contexto do técnico. Imagina a minha aula mais bagunçada, onde os alunos ficam de pé. Eu acho que fico muito com esta imagem. Mas da parte dos alunos eles agradecem, porque foi um momento necessário no meio das situações daquelas disciplinas ali exigentes. (Professora Frida) 
Nesta fala da colaboradora, é visível sua percepção em relação à importância da arte para os alunos por ser um momento diferente das outras disciplinas. Refere-se, assim, a um momento necessário para outras experiências. Não significa que arte não tenha suas exigências e ciências, mas ela trabalha com a subjetividade, a sensibilidade e o aprendizado através da experiência estética.

\begin{abstract}
A grande maioria dos professores não se dá conta de o quanto arte beneficia os alunos. Porque aí a gente já vai entrar na história do ensino de arte neste país que sabemos exatamente o que foi que aconteceu e o por quê a gente tem estes ranços ainda persistentes hoje. (Professora Frida).
\end{abstract}

Nesse relato percebemos que a professora menciona sobre o histórico do ensino de arte e as lutas da área. Algumas imagens ainda podem estar atreladas à arte como um enfeite, decoração ou livre-fazer. Estas imagens que reverberam não condizem mais com a situação atual no ensino, pois hoje trabalhamos com a construção do conhecimento em arte, a crítica, a reflexão e não com técnicas prontas. Supõe-se no relato da colaboradora que a desvalorização da arte está ligada ao histórico tecnicista e expressionista da área.

No contexto nos Institutos Federais, como já mencionado antes, há uma carga-horária alta para os outros componentes curriculares. Neste sentido, para o ensino de arte há um menor espaço, segundo a fala da colaboradora, ela traz "meu único período de arte" e significa a insatisfação de espaço que sente em relação à arte dentro da instituição.

\begin{abstract}
No momento em que eu cheguei ao final do ano eu fiz uma atividade de arte moderna que os outros professores ficaram assim: sem respostas. Eles não acreditaram que aquilo foi feito por aqueles alunos deles, um período de arte por semana, um "períodinho" (suspiros), não acreditaram, foi um trabalho belíssimo, os painéis deste tamanho todos de uma pesquisa. (Professora Frida).
\end{abstract}

Em relação à instituição a professora a considera muito importante por ter o currículo integrado para a formação plena do sujeito, porém ainda destaca algumas questões que a desmotivam em relação à estrutura e a baixa carga-horária de arte:

A instituição é maravilhosa foi tudo muito bem pensado, o aluno recebe toda formação básica junto com o técnico. Mas arte está ali no currículo, por questão de lei até, senão não teria, pois é só um período. Se não fosse a lei não teria, mas a sensação é que não teria. Mas a situação que está é necessário, mas tem arte no currículo por força de lei, eu sinto que 
é incômodo parece, porque teria que ter mais matemática, para o componente técnico. "coloca ali um período de arte" para contemplar a lei... (Professora Frida).

Sobre a legislação, Barbosa (2007) menciona a Lei de Diretrizes e Bases da Educação Nacional (LDBN), Lei n. 9.394/96 que, no parágrafo $2^{\circ}$ do artigo 26, traz a obrigatoriedade da arte na educação básica, mas não cita especificamente que existe a necessidade do ensino de arte em todos os anos de ensino: " $\S 2^{\circ} \mathrm{O}$ ensino da arte, especialmente em suas expressões regionais, constituirá componente curricular obrigatório da educação básica." Esta brecha da lei acarreta autonomia às instituições de ensino a colocarem arte em apenas um ano do ensino médio, por exemplo.

A repetição na fala da colaboradora sobre como a arte é vista de forma "intrusa" no cenário técnico, percebe-se que há uma insatisfação por ser por "força de lei" estar ali. A imagem que a docente tem em relação a esta situação acaba sendo a de resistir a essa defasagem.

Segundo Castoriadis (1982), toda sociedade possui sua simbologia. Compreender a simbologia de uma sociedade é compreender as suas significações imaginárias, pois "O mundo social é constituído e articulado em função de um sistema de significações, e essas significações existem uma vez constituídas na forma do que chamamos o imaginário efetivo (ou o imaginado)". (p.177).

Para este mesmo autor o papel destas significações imaginárias é dar respostas àquelas perguntas pelas quais nos organizam enquanto social: "quem somos nós como coletividade? Que somos nós uns para os outros? Onde e em que somos nós? Que queremos, que desejamos, que nos falta?" (CASTORIADIS, 1982, p. 177) É apenas no fazer de cada sociedade que surgem as "respostas" significativas a estas perguntas, respostas que nunca estão explícitas, mas estão implícitas nas ações cotidianas, nos silêncios, nos vestígios subentendidos de uma história, estão presentes nas práticas e nas relações sociais, mesmo sem a consciência de sua existência no social.

Através do pensamento de Castoriadis (1987) o que se percebe é que o imaginário não provém de um sujeito isolado, único, mas do social. Do mesmo modo Machado (2010) traz a noção de imaginário como ideia de partilha e contágio, onde faz parte da nossa vida, mas não o percebemos, e quase tudo que fazemos é por força de um imaginário.

Quando a colaboradora traz a noção da desvalorização do ensino de arte como algo que está ainda relacionado ao histórico de lutas do ensino, isso demonstra o quanto esta imagem precisa ser modificada, não é mais o nosso tempo, não são mais as nossas necessidades de hoje. Precisamos de outro olhar, uma nova imagem sobre o ensino de arte, principalmente no que tange ao ensino profissional.

Ferreira (1999) fez a sua pesquisa em relação à desvalorização docente vinculada assim ao imaginário social. Este traz como o Jornal de 
grande circulação no Rio de Janeiro veiculou a imagem do professor do "sagrado" ao "profano" até os dias mais recentes.

Esta desvalorização que era veiculada pela mídia mina o imaginário social e as representações de docência. Como um professor que se sente desvalorizado vai movimentar a sua prática de ensino? A partir do que este professor perceber de si, do seu trabalho e de como o veem, influencia no modo como qualifica a sua docência.

A colaboradora deixa esclarecida novamente a dualidade na sua representação. Pois, para ela há uma dúbia realidade de como se sente e de como a sociedade em toda a sua conjuntura encara e trata a docência em arte:

\begin{abstract}
A realização que eu sinto como professora, mas tem tristeza, tem decepção, aquilo de você não conseguir fazer as coisas, impotência, esta situação política que nós estamos hoje. E isso dói.... a desvalorização nossa...desvalorização total desta conjuntura. Mas qual é minha realização? É dizer para os meus filhos que eu como uma professorinha de arte consegui sustentar quatro filhos. Isso não tem preço. Se você tem o que você tem foi sua mãe "professorinha de arte" que ninguém, mas ninguém valoriza, desconhece o trabalho e nem sabem o que você faz, que qualquer um pode dar aula de arte. (Professora Frida).
\end{abstract}

Nesta fala esclarece a forma que está impregnada em um imaginário em relação à profissão professor de arte e a desvalorização "que qualquer um pode dar aula de arte." Esta situação repete-se ainda nos nossos dias atuais, mas sabemos que o trabalho com o ensino de arte como em qualquer outra área demanda de formação específica e habilidades que estão vinculadas a este profissional. Segundo Nóvoa (2009) a visão da docência como vocação e missão faz com que esta não tenha a devida valorização, apesar de o professor ter seus saberes específicos e pedagógicos ele não é reconhecido socialmente.

$\mathrm{Na}$ conclusão do trecho a colaboradora traz em como ainda a esperança de ver este cenário de desvalorização modificado e ainda pode ser revisto. Porque não podemos, principalmente em educação pensar a formação de professores sem olhar para mudanças:

Isso dói, isso coloca a gente assim lá embaixo. Mas temos o potencial de dar a volta por cima e não desistir nunca. (Professora Frida).

O potencial de não desistir nunca, significa que é necessário reverter a situação, é preciso repensar. Neste momento, referimo-nos ao pensamento de Brancher (2010) que traz o imaginário também como força de mudança e criação como este fosse algo possível de modificar: "[...] se não concordamos com certa sociedade que está posta poderíamos pensar uma nova. Ou seja problematizar o Imaginário instituído e partir na busca de um Imaginário 
Instituinte." (BRANCHER, 2010, p. 34) Isso significa que precisamos pensar a educação a partir da criação, poder pensar a formação de professores como possibilidade e potência para criação.

Os dados coletados mostram a importância de se compreender melhor a identidade docente através de suas representações. Deste modo, pode-se atuar de forma mais eficiente na formação de professores. Se os Institutos Federais possuem como objetivo a integração curricular e a formação integral e plena, é pertinente pensar também nos desafios que estão postos aos professores neste contexto.

A aproximação com as perguntas "o que é ser professor de um Instituto Federal?", "como me vejo e percebo o ensino no Instituto Federal?" direcionam as respostas para a reflexão da atuação do docente. As representações que os professores possuem de sua profissão são elementos de sua identidade docente. Assim, Placco e Souza (2010, p. 23) afirmam que "não é possível conceber a aprendizagem do adulto, sobretudo, do adulto professor sem considerar seu processo de formação identitária".

\section{CONSIDERAÇÕES FINAIS}

Os dados coletados da narrativa serviram como base para discutir o quanto na educação profissional é preciso pensar sobre a formação de professores e o quanto isso pode reverter em suas práticas de ensino. A partir da análise de conteúdo e interpretação dos dados ficou explícito que para a professora de arte, na verdade o contexto da educação profissional é desafiador.

Do mesmo modo, foi possível perceber o quanto há alta carga-horária para alguns componentes curriculares e para a arte não há um espaço considerável. Isso demonstra que a integração precisa ser trabalhada e discutida entre os docentes. A formação permanente de professores deve acontecer para que assim como traz Moura (2008) estejam conscientes de seu papel para a transformação social, para a efetivação da práxis educativa. As representações de docência são interessantes para a formação contínua, pois assim aproximamo-nos das suas identidades, valores, necessidades e do que está implícito em seus modos de perceber a docência.

As narrativas da colaboradora demonstram que ainda persiste uma visão desvalorizada do ensino de arte. Na educação profissional, se deve lutar pela integração dos saberes é preciso reverter a visão já ultrapassada da arte apenas como mero-fazer. Nas falas da colaboradora sobre a arte há uma insatisfação que impera e que por isso precisa ser mudada.

A arte na atualidade possui outras bases teóricas, ela é essencial para a compreensão crítica da realidade, a percepção estética, para a criatividade, a sensibilidade. A arte pode dialogar com outras áreas do conhecimento, se houver abertura e incentivo institucional para que a integração aconteça. 
Não há receita pronta para que se revertam todas as necessidades educativas. Mas há possibilidade de se desenvolver a formação permanente dos professores atuantes na educação profissional, onde na coletividade possam transformar e trazer à tona seus anseios e propor melhorias.

\section{REFERÊNCIAS}

ANDRÉ, Marli. Formação de professores: a constituição de um campo de estudos. Educação, Porto Alegre, v. 33, p. 6-18, set./dez. 2010.

BARBOSA, Ana Mae. Inquietações e mudanças no ensino da arte. São Paulo: Cortez, 2007.

BARDIN, Laurence. A Análise de Conteúdo. São Paulo: Edições 70, 2016.

BRANCHER, Vantoir et al. Imaginário e Formação de Professores: Olhares Entrelaçados a partir de Gaston Bachelard e Juremir Machado da Silva. I Encontro Ouvindo Coisa: Pensando outras formas de estar juntos, Santa Maria, 2010.

BRANCHER, Vantoir; OLIVEIRA. Valeska. (Re) Simbolização da docência: entre imaginários e saberes na defesa do protagonismo dos professores. In: BRANCHER, Vantoir; OLIVEIRA. Valeska (orgs) Formação de Professores em Tempos de Incerteza: Imaginários, Narrativas e Processos Autoformadores. Jundiaí: Paco editorial, p.29-48, 2017.

BRASIL. Lei de Diretrizes e Bases da Educação Nacional. Lei n. 9.394, de 20 de dezembro de 1996.

BRASIL. Lei $n^{\circ} 11.892$ de 28 de dezembro de 2008. Dispõe sobre a criação dos Institutos Federais de Educação, Ciência e Tecnologia.

CANDAU, Vera. A didática em questão. Rio de Janeiro: Ed. Vozes, 2012.

CASTORIADIS, Cornelius. A instituição imaginária da sociedade. Tradução de Guy Reynauds. Rio de Janeiro: Paz e Terra, 1982.

FREIRE, Paulo. Pedagogia do Oprimido. Rio de Janeiro: Ed. Paz e Terra, 1970.

FUSARI, Maria F. R.; FERRAZ, Maria H. C. T. Arte na educação escolar. São Paulo: Cortez, 1992.

GARCIA, Marcelo. Desenvolvimento profissional: passado e futuro. SísifoRevista das Ciências da Educação, n. 08, p.7-22, jan/abr. 2009.

GAUTHIER, Clemont. Por uma teoria da pedagogia: Pesquisas Contemporâneas sobre o saber docente. Editora Unijuí. 2008.

IMBERNON, F. Formação continuada de professores. Porto Alegre: Artmed, 2010.

MACHADO, Juremir. As Tecnologias do Imaginário. Porto Alegre: Editora Sulina, 2006. 
MALDANER, Jair. A formação docente para a educação profissional e tecnológica: Breve caracterização do debate. Revista Brasileira de Educação Profissional e Tecnológica. v.2 n. 13, p.182-195, 2007.

MOURA, Dante. A formação de docentes para a educação profissional e tecnológica. Revista Brasileira de Educação Profissional e Tecnológica v.1, n.1 (2008).

NARVAES, Andréa. Significações da Profissão Professor. In: OLIVEIRA, Valeska. (org.). Imagens de Professor: Significações do trabalho docente. ljuí: Editora Unijuí, 2000.

NOVOA, António. Professores imagens do futuro presente. Lisboa: Educa. 2009.

PLACCO, V.M.N. de S. e SOUZA, V.L.T. de. Identidade de professores: considerações críticas sobre perspectivas e suas possibilidades na pesquisa. In: CORDEIRO, A. F. M., HOBOLD, M. de S., AGUIAR, M. A. L. de. Trabalho docente: formação, práticas e pesquisas. Joinville, Editora UNIVILLE, 2010, p. 79-99.

TARDIF, Maurice. Saberes docentes e formação profissional. 9. ed. Petrópolis, RJ: Vozes, 2008.

TRIVIÑUS, Augusto. Introdução à pesquisa em Ciênciais Sociais. São Paulo: Atlas, 1987. 